\title{
EFFECT OF TEMPERATURE AND MULTIWALLED CARBON NANOTUBES CONCENTRATION ON THERMOPHYSICAL PROPERTIES OF WATER BASE NANOFLUID
}

\author{
MOHIT THAKUR ${ }^{1}$, D. GANGACHARYULU ${ }^{2}$ \& GURPREET SINGH ${ }^{3}$ \\ ${ }^{1,3}$ Department of Mechanical Engineering, Chandigarh University, Gharuan, Punjab, India \\ ${ }^{2}$ Chemical Engineering Department, Thapar University, Patiala, Punjab, India
}

\begin{abstract}
Nanofluids can be used as the heat transfer fluid due to itsexceptional thermal properties. The paper investigated the various thermophysical of MWCNT-water nanofluid, when dispersed in water at various temperatures and particle concentration. The nanofluids are prepared by two-step method with gum arabicused as a surfactant to provide strength to the nanoparticles in base fluid. The thermophysical properties were measured using different volume concentrations $\left(0-0.8\right.$ vol. \%) of nanoparticles at various temperatures $\left(30^{\circ} \mathrm{C}\right.$ to $\left.70^{\circ} \mathrm{C}\right)$. KD2 Pro Thermal Property Analyser, Differential Scanning Calorimeter, KEM-DA 130N - Portable density meter, Brookfield LVDV-III ultraprogrammable viscometer devices were used for the measurement of thermal conductivity, specific heat, density, viscosity respectively. The density, viscosity and thermal conductivityincreases as MWCNT's concentrationincreases, on the other hand specific heat was found to decline with particle concentration. Similarly, the thermal conductivity and specific heat increases with a rise in temperature whereas the viscosity and density decreases.

KEYWORDS: Thermo physical Properties, Nanofluids \& MWCNT
\end{abstract}

Received: Jun 09, 2017; Accepted: Jul 04, 2017; Published: Jul 18, 2017; Paper Id: IJMPERDAUG201716

\section{INTRODUCTION}

The increase in demand is due to the over exploitation of energy resources leading to rise of advancement techniques in various thermal systems. The most vital component in any energy efficient machine is its thermal system and the heat transfer fluid used in it. The conventional heat transfer fluids like ethylene glycol and water possesses poor thermal properties when used for cooling and heating applications. Due to its poor thermal properties, an establishment of different heat transfer fluid [1] comprises of a base fluid and a dispersed phase. Nanofluids are the dispersed nanoparticles in the base fluid; it had drawn a lot of kindness as potential heat transfer fluids due to their high thermal conductivity than that of the base fluid [2]. An increase in the thermal conductivity of the solid particles when dispersed in the liquid mixture was first proposed by Maxwell [3]. These nanofluids possesses large thermal conductivity and long-time stability at low particle concentration. An enhancement of $20 \%$ in thermal conductivity was recorded by Lee et al. [4] when suspended $\mathrm{CuO}$ nanoparticles of $4 \%$ volume and $35-\mathrm{nm} \mathrm{CuO}$ particles in ethylene glycol. Over the years, we have been using numerous nanoparticles like $\mathrm{Al}_{2} \mathrm{O}_{3}, \mathrm{CuO}, \mathrm{Al}, \mathrm{Cu}, \mathrm{SiO}_{2}$, carbon nanotubes etc. Among these various nanoparticles, carbon nanotubes (CNT) is a best choice due to its outstanding and exclusive properties like high thermal conductivity of 2000-3000 W/m-K and high aspect ratio [5]. Choi et al. [6] examined an increment of $160 \%$ in thermal conductivity, when $1 \%$ of carbon nanotubes are discharged in engine oil. Das et al. [7] performed an experiment in 
which they found an enhancement inthermal conductivity of nanofluid with a rise in temperature. Ding et al. [8] noted an enhancement in viscosity and thermal conductivity with temperature rise and nanoparticle concentration when the CNT nanoparticles are dispersed in the nanofluid uniformly in a straight copper tube, which further acquires large convective heat transfer improvement under a streamline flow in relation to water for low Reynolds number and weight fraction in nanotubes. There have been many investigations in previous few years, regarding the thermal conductivity enhancement, when CNTs were added in ethylene glycol, poly oil and water, which saw an enhancement of $15 \%$ to $160 \%$ in thermal conductivity at small volume concentration $[9,10,11,12]$.

Nanofluids due to their exceptional features finds wide range of applications in the area of heat transfer technology. Zang et al. [13] investigated thermal conductivity ratio and suspensions stability of CNT/EG based nanofluid and studied the mechanism that increases the suspension stability and decreases sedimentation rates. Their results showed that the surface alteration of carbon nanotubes further lead to improved stability of CNT/EG nanofluid. Farbod and Ameneh [14] studied the thermal conductivity of decorated MWCNT nanofluidand found it much higher than theundecorated one. The water based silver ( $\mathrm{Ag}$ ) decorated carbon nanotubes have absorbed a maximum enhancement of $20.4 \%$ at $4 \mathrm{wt} \%$ and $40^{\circ} \mathrm{C}$. Pryazhnikov et al. [15] experimentally measured the thermal conductivity of nanofluids at $25^{\circ} \mathrm{C}$ using various nanoparticles and base fluids like $\mathrm{SiO}_{2}, \mathrm{Al}_{2} \mathrm{O}_{3}, \mathrm{CuO}, \mathrm{ZrO}_{2}, \mathrm{TiO}_{2}$, diamond and water, ethylene glycol engine oil. They stated that nanofluids thermal conductivity is aentangled capacity and it cannot be described with the classical theory including Maxwell's. They confirmed that greater the nanoparticles density greater the thermal conductivity of the nanofluid and lower the thermal conductivity of the base fluid higher the relative thermal conductivity of its nanofluids. Vafaei et al. [16] examined the thermal conductivity of the hybrid nanofluidMgO-MWCNT/EG using optimal artificial neural network (ANN) at various volume fraction and $25-50^{\circ} \mathrm{C}$ temperature. Their results showed that the best model among the four hidden layer was the one with 12 neurons and there is a maximum deviation of $0.8 \%$. Halelfadl et al. [17] experimentally evaluated various heat transfer properties of MWCNT-water/EG nanofluid in a coaxial heat exchanger under a laminar flow at constant operating temperature. They also studied the effect of nanotubes aspect ratio, surfactant and base fluids on viscosity and thermal conductivity. Their results showed nanofluids shear thinning behaviour, with an increase in aspect ratio of nanotubes the thermal conductivity and average convective heat transfer of nanofluid increases. On the other hand, the viscosity increases when distilled water and ethylene glycol is used as base fluid in comparison to others.

Ruan and Jacoby[18] studied the various heat transfer properties of multiwalled carbon nanotube (MWCNT) nanofluid with a low volume concentration of 0.24 in inter-tube falling film flow. They found higher enhancement with ethylene glycol than water in laminar flow at same Reynolds number. They also investigated the relation between the volume concentration and heat transfer coefficient. Suresh et al. [19] synthesize $\mathrm{Al}_{2} \mathrm{O}_{3}-\mathrm{Cu}$ hybrid nanofluid by thermochemical method and experimentally investigated that the compelling thermal conductivity of the hybrid mixture is more than that deionized water which further it enhances with a rise in nanoparticles volume concentration. They also found that with a rise in viscosity of the nanofluidit starts behaving as a Newtonian fluid and the viscosity of the prepared mixture is more than that of Alumina water mixture.Ganesh et al. [20] noted the effect of MWCNT nanoparticles dissolved in water-ethylene glycol mixture on its various thermophysical properties. The results showed, an enhancement of $11 \%$ in thermal conductivity was noted at $0.9 \%$ concentration and the thermal conductivity increase with rise in concentration, and there is also a decrease in specific heat with an increase in concentration, while viscosity ratio increases with rise in temperature. M.Tajik and Zamzamian [21] used the thermal property analyser to measure the thermal conductivities of 
$\mathrm{Cu} /$ water and $\mathrm{Al} /$ water nanofluids. The results showed that the thermal conductivity of $\mathrm{Cu} /$ water nanofluid is higher than that of $\mathrm{Al} /$ water nanofluid, they also found that the nanofluids are having higher thermal conductivity in comparison to base fluid.

Atashrouz et al. [22] tentatively analysed the effect of shear rate on the viscosity of the ethylene glycol/water $/ \mathrm{Fe}_{2} \mathrm{O}_{3}$ nanofluids and studied the rheological behaviour of the nanofluids. They found a decrease in viscosity with an increase in shear rate. Further, for they used a hybrid group method of data handling polynomial neural network for predicting the viscosity.Namburu et al. [23] experimentally inspected the specific heat and the viscosity of $\mathrm{SiO}_{2}$ (silicon dioxide) nanoparticles of diameters (20, 50 and $100 \mathrm{~nm}$ ) within $60 \%$ ethylene glycol and $40 \%$ water mixture (by weight). The data showed the new interaction which links viscosity with the nanofluid temperature and the particle volume fraction. Priya et al. [24] experimentally noted the thermal conductivity of CuO-water nanofluid at $28^{\circ} \mathrm{C}$ and $55^{\circ} \mathrm{C}$ respectively and reported an enhancement of about $13 \%$ and $44 \%$ in thermal conductivity at $28^{\circ} \mathrm{C}$ and at $55^{\circ} \mathrm{C}$.Sundar et al. [25] tentativelyexamined the thermal conductivity of low volume concentration CuOand $\mathrm{Al}_{2} \mathrm{O}_{3}$ nanofluids taking water and ethylene glycol mixture (50:50) as a base fluid at various temperatures and volume concentrations and reported that the thermal conductivity of $\mathrm{CuO}$ was found to be more than $\mathrm{Al}_{2} \mathrm{O}_{3}$ under same temperature and volume concentration. Few other experimental studies which discusses the various thermophyscial properties of nanofluids at various temperatures and concentrations has also been discussed, they found an enhancement in thermal conductivity with a rise in temperature and particle concentration, which is due to the increase in Brownian movement with a rise in temperature [26, 27, 28]. Haddad et al. [29] noted the effects of Brownian motion in nanofluid in the heat transfer enhancement. The authors used two nonhomogenous equilibrium models for nanofluid which incorporates the effects of thermophoresis andBrownian motion.

From the above literature, it is found that there is a rise in thermal conductivity and specific heat with rise in temperature, whereas, viscosity and density decreases with rise in temperature and other thingsalso have to be kept in mind regarding the use of carbon nanotubes as the heat transfer fluid. The aim of study is measure the different thermophysical properties of water based MWCNT nanofluids at different temperatures ranging from $\left(30-70^{\circ} \mathrm{C}\right.$ with an interval of $\left.10^{\circ} \mathrm{C}\right)$ and particle concentration $(0 \%, 0.2 \%, 0.4 \%, 0.6 \%$ and $0.8 \%)$ which can be used for the different heat transfer equipment's.

\section{NANOFLUID PREPARATION}

Table 1. listed some characteristics of CNT. In the present study, the nanofluid with various carbon nanotubes particles concentrations $(0,0.2,0.4,0.6$ and $0.8 \mathrm{v} / \mathrm{v})$ were prepared. The gum arabic is used as a surfactant, de-ionized water (DIW) was as the base fluid and multiwalled carbon nanotubes (MWCNT) as nanoparticles. The surfactant were used to increases the stability of nanoparticles in aqueous mixture and most important to remove the agglomerations and modification of nanoparticles in the nanofluids. The major part is to add the proper amount of surfactant, which could coat the CNTs surface. The stability of the nanofluids were determined by UV spectroscopy. A $0.25 \mathrm{wt} \%$ of surfactant was added to base fluid and was then magnetically mixed for 60 minutes, further the multiwalled carbon nanotubes nanoparticles were added to the solution. The solution was then transferred to the ultrasonicator for sonication to achieve a uniform dispersion of the particles in the base fluid. The sonication was done by ultrasonicator which was placed in a water bath at $20 \mathrm{kHz}$ frequency for almost 3 hours. 
Table 1: Characteristics and Geometrical Specifications of Multiwalled Cnt's

\begin{tabular}{|l|l|}
\hline MATERIAL & \multicolumn{1}{c|}{ MWCNT } \\
\hline Appearance & Black \\
\hline Purity & $>98 \%$ \\
\hline Diameter & $18-20 \mathrm{~nm}$ \\
\hline Length & Av. $20 \mu \mathrm{m}$ \\
\hline SSA & $330 \mathrm{~m}^{2} / \mathrm{g}$ \\
\hline Density & $0.20-0.35 \mathrm{~g} / \mathrm{cm}^{3}$ \\
\hline
\end{tabular}

\section{EXPERIMENTAL PROCEDURE}

\section{Thermal Conductivity}

The measurement of thermal conductivity with respect to different temperature is the most important factor for the assessment of convective heat transfer coefficient for numerous operations. Various methods are used for the measurement of thermal conductivity like hot wire method or transient hot wire method (THW), cylindrical cell method, temperature oscillation method. The thermal conductivity was measured using KD2 Pro Thermal property Analyser (Decagon Devices Inc., USA). Transient line heat source method is used to measures thermal conductivity. KD2 Prodwells of a sensor needle and a micro-controller. The sensor is known as $\mathrm{KS}-1$ sensor which is $1.2 \mathrm{~mm}$ in diameter and $60 \mathrm{~mm}$ long it consists of a heating element and a thermostat, the sensor is further used to measure nanofluids thermal conductivity ranging from 0.002 $-2.00 \mathrm{~W} / \mathrm{m} . \mathrm{K}$, accuracy $\pm 5 \%$. A controller bath with an accuracy of $\pm 0.01{ }^{\circ} \mathrm{C}$ was used for maintaining the desired temperature of the nanofluids. A $25 \mathrm{ml}$ nanofluid was poured into a cylindrical shape glass container and a flexible nylon lid was fitted on the container through which the sensor needle was embedded right at the centre and a scan time of 60 sec. was configured for measurement. All the measurements were taken, when the nanofluids attain the desired temperature and every reading is taken thrice and an average value was taken into consideration.

\section{Specific Heat}

The specific heat of MWCNT nanofluid was measured using DSC 4000 model (Differential Scanning Calorimeter, Perkin Elmer, USA). Specific heat at various concentrations ranging from $0 \%, 0.2 \%, 0.4 \%, 0.6 \%$ and $0.8 \%$ vol. $\%$ and temperatures $30,40,50,60$ and $70^{\circ} \mathrm{C}$ were measured. A $22 \mathrm{mg}$ of nanofluid sample was placed on the aluminium pan with a scanning rate of $3^{\circ} \mathrm{C} \mathrm{min}^{-1}$. The reading are measured thrice and finally an average value is considered. The following equation (1) has used for comparison with the experimental readings.

$$
\left(C_{p}\right)_{n f}=\frac{(1-\varphi) \rho_{f} C_{p \cdot f}+\varphi \rho_{p} C_{p \cdot p}}{\rho_{n f}}
$$

\section{Density}

The density of MWCNT based the nanofluid was measured with the help of a KEM-DA 130N (a portable density meter) having a range $0-2000 \mathrm{~kg} / \mathrm{m}^{3}$. A nanofluid ranging from $(0 \%, 0.2 \%, 0.4 \%, 0.6 \%$ and $0.8 \%)$ volume concentration under a temperature ranges of $30-70^{\circ} \mathrm{C}$ was measured with a precision of $\pm 0.001 \mathrm{~kg} / \mathrm{m}^{3}$. All the values are taken thrice for more precision and then further an average value is used for calculations. The experimental value of the density is then compared with the model which uses the equation (2).

$$
\rho_{n f}=(1-\varphi) \rho_{f}+\varphi \rho_{p}
$$




\section{Viscosity}

Brookfield LVDV-III ultra-programmable viscometer was used to measure the viscosity of the MWCNT-water nanofluid at various concentrations and temperatures. The Brookfield LVDV-III viscometer was further connected to a personal computer which for collecting and storing data. The device provides the flow factor like shear stress and viscosity at given shear rate. The spindle which was attached to the viscometer was further inserted into to the sample jacket containing the nanofluid. Due to the deflection of the calibrated spring a viscous drag was created against the spindle. The instrument measures the values with an accuracy of $\pm 1.0 \%$. The device uses a spindle model of ULA-49EAY type and the adapter is used to circulate the temperature of the bath. The viscosity was measured from 0 to 0.8 vol.\% with temperature from $30-70^{\circ} \mathrm{C}$ at an interval of $10^{\circ} \mathrm{C}$. Three reading has been taken at each point and the average to the values is presented for analysis.

\section{RESULTS AND DISCUSSIONS}

\section{Thermal Conductivity}

The thermal conductivity of MWCNT-water nanofluid at different concentrations $(0 \%, 0.2 \%, 0.4 \%, 0.6$, and $0.8 \%$ ) and temperatures $\left(30,40,50,60\right.$ and $\left.70^{\circ} \mathrm{C}\right)$ is shown in figure 1 . There is a rise in thermal conductivity ofthe nanofluid and the base fluidwith an increase in temperature and the volume concentration. The data shows a higher thermal conductivity for the nanofluids in contrast to the base fluid at different volume concentration, this happens due to the random Brownian motion of the nano-sized particles with a rise in temperature. These kinds of results were discussed by Xiao et al. [30]. The major reason behind an enhancement in thermal conductivity of CNT based nanofluid is due to the CNT nanoparticles. The base fluid at $30^{\circ} \mathrm{C}$ possesses thermal conductivity of $0.619 \mathrm{~W} / \mathrm{m}-\mathrm{K}$ and at same temperature the nanofluids at 0.8 vol. \% maintains a thermal conductivity of $0.692 \mathrm{~W} / \mathrm{m}-\mathrm{K}$ which is $12 \%$ higher than the base fluid. The results clearly shows that with an increase in volume concentration the thermal conductivity increases of the nanofluids. The similar trends with higher enhancement were discussed by Choi et al. [10] and Xie et al. [11]. At the highest temperature the thermal conductivity of the base fluid and 0.8 vol. \%were $0.660 \mathrm{~W} / \mathrm{m}-\mathrm{K}$ and $0.800 \mathrm{~W} / \mathrm{m}$-Krespectively with an enhancement of $23 \%$. The similar results at lower concentration was also shown by Xing et al. [31] with a thermal conductivity of $8.1 \%$ for S-SWCNT, $16.2 \%$ for L-SWCNT, $5.0 \%$ for MWCNT. Form the above data it has been observed thatthermal conductivity of nanofluid at different temperatures and volume concentration is having anincreasing trend. The higher surface area of CNT nanoparticles is also one of the main reason for enhancing thermal conductivity as it gives expansive contact area with its base fluid, which further lead to reduction of contact resistance in CNT's fluid interface. 


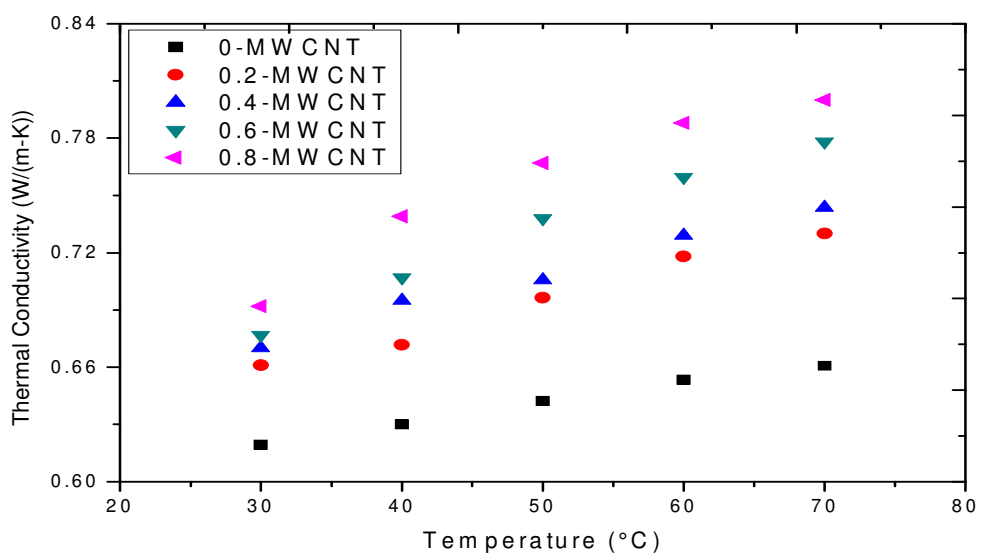

Figure 1: Thermal Conductivity of MWCNT's Nanofluid at different Temperatures and Concentrations

\section{Specific Heat}

The specific heat measurement of the base fluid and the nanofluid at various concentrations $(0 \%, 0.2 \%, 0.4 \%$, $0.6 \%$ and $0.8 \%)$ and temperatures $\left(30^{\circ} \mathrm{C}, 40^{\circ} \mathrm{C}, 50^{\circ} \mathrm{C}, 60^{\circ} \mathrm{C}, 70^{\circ} \mathrm{C}\right)$ is shown in figure 2 . The specific heat tends to increase with a rise in temperature and the trend was consistent. But, when the volume concentration increases the specific heat decreases due to low specific heat of the added particles contrasted with the base fluid.

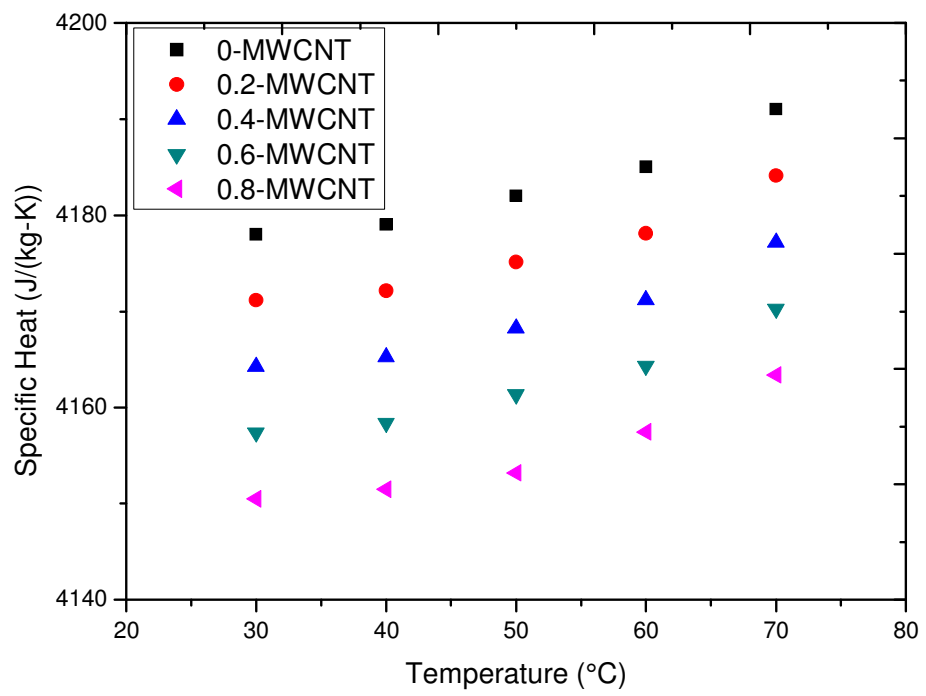

Figure 2: Specific Heat of MWCNT's Nanofluid at Different Temperatures and Concentrations

The specific heat of base fluid at $30^{\circ} \mathrm{C}$ and $70^{\circ} \mathrm{C}$ were $4178 \mathrm{~J} / \mathrm{kg} . \mathrm{K}$ and $4191 \mathrm{~J} / \mathrm{kg} . \mathrm{K}$, on the other hand $0.8 \%$ vol. concentration nanoparticles at $30{ }^{\circ} \mathrm{C}$ and $70^{\circ} \mathrm{C}$ temperature possesses a specific heat of $4150.49 \mathrm{~J} / \mathrm{kg} . \mathrm{K}$ and 4163.37 $\mathrm{J} / \mathrm{kg}$.K. From the values it means, the quantity of heat required to rise the temperature of the nanofluid is nearly lower in comparison to the base fluid. It can be seen that gaps between the two concentrations were same but the gap between two declining lines were not same. The similar trend were also shown by Elias et al. [32], they figure out a reduction of 5.08\% in specific heat of $\mathrm{Al}_{2} \mathrm{O}_{3}$ nanoparticles at $1.0 \%$ vol. concentration, a deviation of $4.5 \%$ in experimental value from the 
theoretical value were measured by them. Ganesh et al. [20] also found a reduction of $28 \%$ at $5{ }^{\circ} \mathrm{C}$ and $23 \%$ at $40{ }^{\circ} \mathrm{C}$ in specific heat with 1.5 wt.\%.

\section{Density}

The figure 3 portrayed the densities of MWCNT - water nanofluid with different temperature $\left(30^{\circ} \mathrm{C}, 40^{\circ} \mathrm{C}, 50^{\circ} \mathrm{C}\right.$, $\left.60^{\circ} \mathrm{C}, 70^{\circ} \mathrm{C}\right)$ and different concentrations $(0 \%, 0.2 \%, 0.4 \%, 0.6 \%$ and $0.8 \%)$. From the data it can be watched that the density of the nanofluid increments with anexpansion in particleconcentration, on the other hand the density decreases with a rise in temperature. The base fluid possess the lowest values of the densities in comparison to the nanofluids. The results predicted the density of the base fluids is $995.2 \mathrm{~kg} / \mathrm{m}^{3}$ at $30^{\circ} \mathrm{C}$ and $977.7 \mathrm{~kg} / \mathrm{m}^{3}$ at $70^{\circ} \mathrm{C}$, similarly the density of the nanofluid in $0.8 \%$ concentration at $30^{\circ} \mathrm{C}$ and $70^{\circ} \mathrm{C}$ were $996.33 \mathrm{~kg} / \mathrm{m}^{3}$ and $978.973 \mathrm{~kg} / \mathrm{m}^{3}$. The measured value are further compared with the equation (2) by taking the density of MWCNT as $2100 \mathrm{~kg} / \mathrm{m}^{3}$ and base fluid as $1066 \mathrm{~kg} / \mathrm{m}^{3}$. The concept of molecular dynamic simulation was presented by Alessio Alexiadis and Stavros Kassinos [33]. They studied that the MWCNT are filled with the base fluids molecules in various forms like wire mode, bulk mode and layer mode which further lead to non-uniform density variation in high interfacial region with higher vander wall forces.

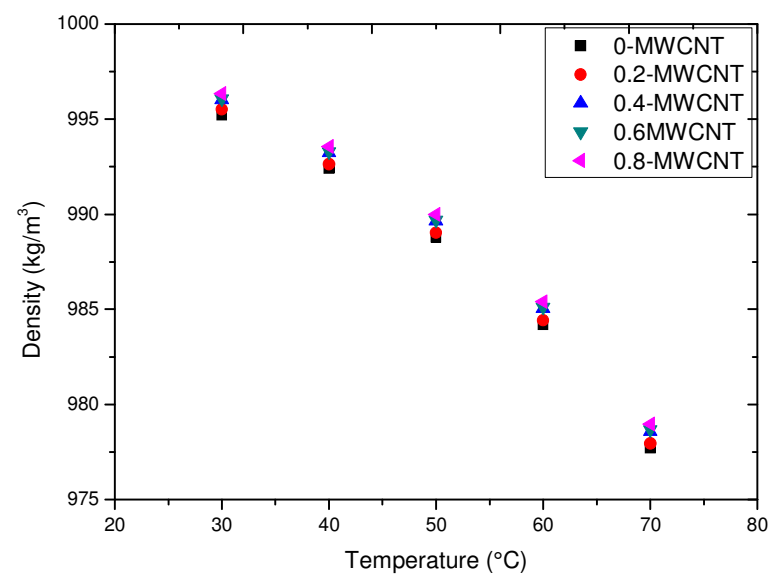

Figure 3: Density of MWCNT's Nanofluid at different Temperatures and Concentrations

\section{Viscosity}

Figure 4 presents the viscosities of MWCNT based nanofluid and the base fluid various temperatures (30, 40, 50, 60 and $70^{\circ} \mathrm{C}$ ) and volume concentrations of nanoparticles ranging from $0 \%, 0.2 \%, 0.4 \%$ and $0.8 \%$ vol. $\%$. The data showsan increase in temperature the viscosity decrease. The base fluid is having a lower viscosity than the nanofluid at various volume concentrations. The viscosity of the base fluid falls upto $47.2 \%$ when the temperature increases from $30^{\circ} \mathrm{C}$ to $70^{\circ} \mathrm{C}$. Whereas nanofluids viscosity decrease by $8.3 \%$ when the temperature is increased from $30^{\circ} \mathrm{C}$ to $70^{\circ} \mathrm{C}$. This is due to the increase in the random action among the molecules of the material. This trend is commonly observed in most of the liquids, as the movement of the molecules are much higher than the viscosity decreases. A Newtonian behaviours is shownby the low concentration of MWCNT nanoparticles in base fluid.

The similar trends were shown by the Kumaresan et al. [34], they found that the viscosity of the nanofluids especially depends upon the aspect ratio and concentration of the carbon nanotube. Elias et al. [32] also discussed the similar decreasing trend of the viscosity exponentially with increasing temperature. A maximum enhancement of $150 \%$ was 
foundfor $1 \%$ volume $\mathrm{Al}_{2} \mathrm{O}_{3}$ - $\mathrm{RC}$ nanofluid at $10^{\circ} \mathrm{C}$ and the lowest $4 \%$ for 0.2 vol. \% nanofluid.

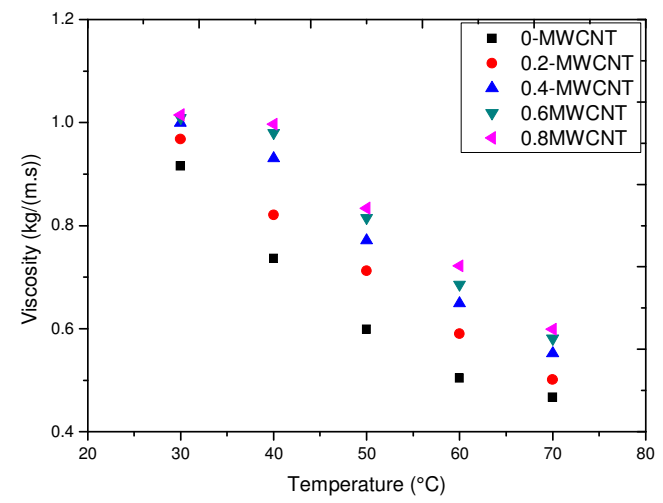

Figure 4: Viscosity of MWCNT's Nanofluid at different Temperatures and Concentrations

\section{CONCLUSIONS}

The thermophysical properties of the multiwalled carbon nanotubes (MWCNT) based nanofluids were measured experimentally, at different temperatures and concentrations, respectively. A rise in thermal conductivity with a rise in temperature from $30^{\circ} \mathrm{C}$ to $70^{\circ} \mathrm{C}$, an enhancement of $23 \%$ was also found at $0.8 \%$ vol. MWCNT. CNT particles are the main reason for the enhancement in thermal conductivity of nanofluid. The specific heat increases with a rise in temperature and further it falls with a rise in particles concentration. Whereas, the density decreases with rise in temperature and it further increases with a rise in particle concentration. Similar trends were also shown by viscosity, as it increases with rise in temperature and diminishes with an increase in MWCNT's concentration in nanofluid.

\section{REFERENCES}

1. Choi, S.U.S.. Enhancing thermal conductivity of fluids with nanoparticles. ASME FED 1995;231:99e105

2. Das, S.K., Choi, S.U.S., Yu, W., Pradeep, T., (2008) Nanofluids. Wiley, Hoboken

3. Maxwell, J.C. Electricity and Magnetism. Oxford: Clarendon Press; 1873.

4. Lee, S.,Choi,S. U. S., Li,S., Eastman, J. A. Measuring Thermal Conductivity of Fluids Containing Oxide Nanoparticles, J. Heat Transfer, vol. 121, pp. 280-289, 1999.

5. Munkhbayar, B., Tanshen, M.D.R., Jeoun, J., Jeong, H., Surfactant-free dispersion of silver nanoparticles into MWCNTaqueous nanofluids prepared by one-step technique and their thermal characteristics, Ceramics International, Vol. 39, (2013), $6415-6425$.

6. Choi, S. U.S., Zhang, Z. G., Yu,W., Lockwood, F. E., Grulke, E. A., Anomalous Thermal Conductivity Enhancement in Nanotube Suspensions, Appl. Phys. Lett., vol. 79, pp. 2252-2254, 2001.

7. S. K. Das, N. Putra, P. Theisen, and W. Roetzel, Temperature Dependence of Thermal Conductivity Enhancement for Nanofluid, J. Heat Transfer, vol. 125, pp. 567-574, 2003.

8. Ding, Y., Hajar, A., Dongsheng, W., Richard, W., Heat transfer of aqueous suspensions of carbon nanotubes (CNT nanofluids), International Journal of Heat and Mass Transfer, Vol. 49 (1), (2006) 240-250.

9. Kim, P., Shi, L., Majumdar, A., McEuen P.L., Thermal transport measurements of individual multiwalled nanotubes, Physical Review Letters, Vol. 87, (2001) 215502. 
10. Choi, S.U.S., Zhang, Z.G., Yu, W., Lockwood, F.E., Grulke, E.A., Anomalous thermal conductivity enhancement in nanotube suspensions, Applied Physics Letter, Vol. 79, (2001) 2252-2254.

11. Xie, H., Lee, H., Youn, W., Choi, M., Nanofluids containing multiwalled carbon nanotubes and their enhanced thermal conductivities, Journal of Applied physics, Vol. 94, (2003), 4967-4971.

12. Liu, M., Lin, M.C., Wang, C., Enhancements of thermal conductivities with $\mathrm{Cu}, \mathrm{CuO}$, and carbon nanotube nanofluids and application of MWNT/water nanofluid on a water chiller system, Nanoscale Research Letters.Vol. 6 (1), (2011), 1-13.

13. Zang P., Hong W., J.F.WU, G.Z. Liu, J. Xiao, Z.B. Chen, H.B. Cheng, Effects of surface modification on the suspension stability and thermal conductivity of carbon nanotubes nanofluids., Energy Procedia 69 (2015) 699-705.

14. Farbod, M., Ahangarpour, A., Improved thermal conductivity of Ag decorated carbon nanotubes water based nanofluids, Physics Letters A 380(2016) 4044-4048.

15. Pryazhnikov M.I., Minakov A.V., Rudyak V.Ya., Guzei D.V., Thermal conductivity measurement of nanofluids, International Journal of Heat and Mass Transfer 104 (2017) 1275-1282.

16. Vafaei, M., Afrand, M., Sina, N., Kalbasi, R., Sourani, F., Evaluation of thermal conductivity of MgO-MWCNTs/EG hybrid nanofluids based on experimental data by selecting optimal artificial neural networks, Physica E85 (2017) 90-96.

17. Halelfadl S, Estelle P, Mare T, Heat transfer properties of aqueous carbon nanotubes in coaxial heat exchanger under laminar regime, Experimental Thermal and Fluid Science 55 (2014) 174-180.

18. Ruan, B., Jacoby, A.M., Heat transfer characterstics of mutiwalled carbon nanotube suspensions (MWCNT nanofluids) in intertube falling-film flow, International Journal Heat Mass Transfer 55 (2012) 3186-3195.

19. Suresh, S., Venkitaraj, K.P., Selvakumar, P., Chandrasekar, M., Synthesis of $\mathrm{Al}_{2} \mathrm{O}_{3}-\mathrm{Cu}$ /water hybrid nanofluids using two step method and its thermo physical properties, Colloids Surf. A 388 (2011) 41-48.

20. Ganeshkumar, J., Kathirkaman, D., Raja, K., Kumaresan, V., Velraj, R., Experimental study on density, thermal conductivity, specific heat and viscosity of water-ethylene glycol mixture dispersed with carbon nanotubes, Thermal Science, Vol. 28, (2015).

21. Jamal-Abadi, M.T. and Zamzamian, A.H., Thermal conductivity of $\mathrm{Cu}$ and Al-water nanofluids, International Journal of Engineering, Transactions B: Application, Vol. 26, No. 8, (2013), 821-828.

22. Atashrouz, S., Mozaffarian, M., Pazuki, G., Viscosity and rheological properties of ethylene glycol + water $+\mathrm{Fe}_{3} \mathrm{O}_{4}$ nanofluids at various temperatures: Experimental and thermodynamics modelling, Korean Journal Chemical Engineering, 33(9), (2016), 2522-2529.

23. Namburu, P. K., Kulkarni,D. P., Dandekar, A., Das,D. K., Experimental investigation of viscosity and specific heat of silicon dioxide nanofluids, Micro and Nano Letters, vol. 2, no. 3, pp. 67-71, 2007.

24. Priya, K. R, Suganthi, K.S., Rajan, K.S., Transport properties of ultra-low concentration CuO-water nanofluids containing non-spherical nanoparticles, International Journal of Heat and Mass Transfer 55 (2012) 4734-4743

25. Sundar, L. S, Farooky, Md., H., Sarada, S.N., Singh, M.K., Experimental thermal conductivity of ethylene glycol and water mixture based low volume concentration of $\mathrm{Al}_{2} \mathrm{O}_{3}$ and $\mathrm{CuO}$ nanofluids, International Communications in Heat and Mass Transfer 41 (2013) 41-46

26. Prashant, Singh, G. and Sarao T.P.S., Experimental Investigation of Heat Transfer Characteristics of Plate Heat Exchanger using Alumina-Water based Nanofluids at Different Orientations, Indian Journal of Science and Technology, Vol 9(48) 
27. Singh, S., Singh, G., Singla, A., Experimental Studies on Heat Transfer Performance of Double Pipe Heat Exchanger with using Baffles and Nanofluids., Indian Journal of Science and Technology, Vol 9(40)

28. Prashant, Singh, G., Sarao., T., Experimental Analysis of Heat Transfer and Friction Factor in Plate Heat Exchanger with Different Orientations Using $\mathrm{Al}_{2} \mathrm{O}_{3}$ Nanofluids, International Journal of Engineering, Transactions A: Basics, Vol. 29, No. 10, (2016) 1450-1458.

29. Haddad, Z., Nada, E.A., H, Oztop, H.F., Mataoui, A., Are the thermophoresis and Brownian motion effects significant in nanofluid heat transfer enhancement, International Journal of Thermal Sciences, 57 (2012), 152-162.

30. Xiao, B., Yang, Yi., Chen L., Developing a novel form of thermal conductivity of nanofluids with Brownian motion effect by means of fractal geometry, Powder Technology, Vol. 239, (2013), 409.

31. Xing, M., Yu, J., Wang, R., Experimantal study on the thermal conductivity enhancement of water based nanofluids using different types of carbon nanotubes, Internaltional Journal of Heat and Mass Transfer, Vol. 88, (2015), 609-616.

32. Elias, M.M., Mahbubul, I.M., Saidur, R., Sohel, M.R., Shahurl, I.M., Khaleduzzaman, S.S., Sadeghipour, S., Experimental investigation on the thermos-physical properties of $\mathrm{Al}_{2} \mathrm{O}_{3}$ nanoparticles suspended in car radiator coolant, International Communication in Heat and Mass Transfer, Vol. 54, (2014), 48-53.

33. Alexiadis, A., Kassinos, S., “The density of water in carbon nanotubes”, Chemical Engineering Science, Vol. 63, (2008), 2047 $-2056$.

34. Kumaresan, V., Mohaideen Abdul Khader, S., Karthikeyan, S., Velraj, R., Convective heat transfer characteristics of CNT nanofluids in a tubular heat exchanger of various lengths for energy efficient cooling/heating system, International Journal of Heat and Mass Transfer, 60 (2013), 413-421.

\section{NOMENCLATURE}

$C_{p}=$ Specific heat

$\rho=$ Density

$\varphi=$ Volume fraction

$f=$ Base fluid

$n f=$ Nanofluid

$p=$ Particle 